\title{
Médiévales
}

Langues, Textes, Histoire

49 | automne 2005

La paroisse, genèse d'une forme territoriale

\section{Laurence Meiffret, Saint Antoine ermite en Italie (1340-1540), programmes picturaux et dévotion}

Rome, École Française de Rome, 2004, 345 p., 99 ill., index des noms de personnes et de lieux, index analytique.

\section{Chloé Maillet}

\section{(2) OpenEdition}

Journals

Édition électronique

URL : https://journals.openedition.org/medievales/1219

DOI : $10.4000 /$ medievales. 1219

ISSN : $1777-5892$

Éditeur

Presses universitaires de Vincennes

Édition imprimée

Date de publication : 1 décembre 2005

Pagination : 178-180

ISBN : 2-84292-177-1

ISSN : 0751-2708

Référence électronique

Chloé Maillet, « Laurence Meiffret, Saint Antoine ermite en Italie (1340-1540), programmes picturaux et dévotion », Médiévales [En ligne], 49 | automne 2005, mis en ligne le 12 mars 2007, consulté le 24 avril 2022. URL : http://journals.openedition.org/medievales/1219 ; DOI : https://doi.org/10.4000/ medievales. 1219

Ce document a été généré automatiquement le 24 avril 2022.

Tous droits réservés 


\title{
Laurence Meiffret, Saint Antoine ermite en Italie (1340-1540), programmes picturaux et dévotion
}

\author{
Rome, École Française de Rome, 2004, 345 p., 99 ill., index des noms de \\ personnes et de lieux, index analytique.
}

Chloé Maillet

Bien que saint Antoine ermite ait été l'objet d'un culte très populaire, il fallut attendre la fin du Moyen Âge pour que se développent des cycles iconographiques narratifs et monographiques à son sujet. Ce type de représentation se rencontre en effet uniquement entre le milieu du quatorzième et le début du seizième siècle. Partant de ce constat, l'auteur en vient à la fois à se poser la question de la prévalence de ce modèle érémitique et de la « récupération » du saint, plus d'un millénaire après sa mort, par les commanditaires religieux et laïcs de la fin du Moyen Âge. Le travail proposé développe ainsi, dans les limites temporelles imposées par le sujet, la présentation d'un corpus de cycles narratifs de la vie de saint Antoine ermite, en Italie, en partant du foyer d'éclosion du culte antonin, le Dauphiné. Les critères du choix des œuvres sont délibérément ceux de la pertinence des représentations par rapport aux «évolutions spirituelles» de l'époque, et non leur prétendue valeur artistique. En cela, Laurence Meiffret s'inscrit dans le récent mouvement de renouvellement des études iconographiques et iconologiques, dans la lignée de travaux tels que ceux de Daniel Russo ou de Dominique Rigaux. De plus, si l'iconographie de saint Antoine parait familière, L. Meiffret s'est vite rendu compte que la bibliographie était assez restreinte sur le sujet en dehors des études spécifiques consacrées aux épisodes de tentation. Le corpus commenté dans cette étude se compose finalement de vingt-huit cycles, répartis entre le Dauphiné et l'Ombrie en passant par le Nord de l'Italie. De nombreuses illustrations (quatre-vingt-dix-neuf, dont trois en couleurs) accompagnent heureusement le propos, bien que l'on eût apprécié de les voir en plus grande taille (elles sont parfois trois par page) et plus souvent en couleurs. 
2 L'étude de L. Meiffret, issue d'une thèse de doctorat soutenue à l'Université Paris 1 sous la direction de Léon Pressouyre, s'ouvre sur un chapitre préliminaire présentant de manière générale le culte de saint Antoine dans l'Occident médiéval, avant d'entamer le commentaire des cycles à proprement parler selon quatre chapitres chronologiques. On voit alors comment cet ermite parmi d'autres se fit l'initiateur du «martyre blanc » et, après qu'eurent été rédigées à son propos de nombreuses vies apocryphes, devint un thaumaturge particulièrement efficace. À partir de ce culte, l'iconographie antonine se serait fondée en deux temps, par l'assimilation des conventions préexistantes de l'érémitisme et ensuite par l'adaptation à des demandes de proximité et de familiarité sous-tendues dans le culte antonin lui-même.

Dans le premier chapitre, l'auteur évoque la genèse des cycles antonins en commentant des cycles de la fin du Trecento et du premier Quattrocento commandés à la fois par des dominicains (San Domenico à Alba), s'appropriant l'ermite par un parallèle entre Vitae patrum et Vitae fratrum, mais aussi des augustins (Sant'Agostino à Montalcino) et des franciscains (San Francesco à Bassano del Grappa, San Francesco à Prato, San Francesco à Montefalco), qui parviennent en quelque sorte à une institutionnalisation de saint Antoine en proto-François. Il est intéressant de noter que, dans la première génération de cycles consacrés à saint Antoine, les représentations de ses miracles et de ses terribles tentations sont très rares. Le programme-type de ces vies tourne autour de six scènes fréquentes: la charité aux pauvres, la bastonnade, la rencontre du centaure, l'embrassade des ermites, le repas miraculeux et la mort du saint.

Le deuxième chapitre s'attache à décrire la propagande des Antonins au début du quinzième siècle et la diversification des ordres commanditaires visible par la suite. Le fait que les premières traces de programmes muraux mettant en scène saint Antoine en milieu antonin ne remontent qu'au premier quart $d u x^{e}$ siècle pourrait s'expliquer, selon l'auteur, par une profonde crise interne provoquée par les répercussions du Grand Schisme : l'ordre ayant à restaurer l'intégrité de sa propre image, et à gommer les dissensions internes, avant de pouvoir se préoccuper d'une véritable politique promotionnelle. Il reste qu'entre 1420 et 1470 environ, on peut trouver un grand nombre de cycles narratifs de la vie de saint Antoine ermite, selon une iconographie réactualisée, de la Toscane à l'Ombrie. L. Meiffret décrit ainsi l'église de Pescia, celle de Buttigliera Alta réalisée par Giacomo Jaquerio, les panneaux siennois du retable du maitre de l'observance, l'église Sant'Antonio de Cascia, et d'autres encore. Parmi les nombreux exemples qu'elle développe, on peut remarquer notamment la découverte du site de Beroide, en Ombrie, à mi-chemin entre Foligno et Spolète, qui présente dans la chapelle privée de Sant'Antonio un cycle tout à fait digne d'intérêt, mais si délaissé par les autorités locales et régionales qu'il est vraisemblablement destiné à disparaître faute de mesures d'urgence (d'autant que le bâtiment a été très déstabilisé par le tremblement de terre de 1997). L'auteur montre également qu'à l'époque de l'apogée cultuel du saint, le florilège d'œuvres présentes en Toscane et en Ombrie relève quasiment de la seule promotion des principales communautés observantes, franciscaine ou augustinienne.

5 Le troisième chapitre propose une série de programmes de la fin du Quattrocento en Italie septentrionale. L'auteur décrit ainsi la chapelle San Fiorenzo de Bastia Mondovi, San Pietro in Gessate à Milan, la prédelle démembrée de Bernardo Parentino, conservée à la galerie Doria Pamphili à Rome, ainsi que le site de Pelugo dans les Alpes, avant de comparer son iconographie avec le théâtre des mystères. Nous voyons ainsi comment 
les images du saint en viennent à constituer une véritable propagande anti-hérétique. On remarque également comment se constituent les premières commandes purement laïques, paroissiale à Beroide ou confraternelle à Assise, qui montrent un ancrage progressif de l'iconographie du saint dans le tissu social, mouvement qui voit son apogée dans les vastes réalisations populaires $d u x v I^{e}$ siècle. Pourtant, de manière générale, la vocation iconographique de saint Antoine est devenue, selon L. Meiffret, à la fin du Quattrocento celle du champion des communautés désireuses soit d'établir une légitimité incontestable (Franciscains, Augustins), soit de restaurer une image un temps ternie (Antonins, Bénédictins).

6 Cet ouvrage s'achève par un chapitre évoquant la diffusion des cycles antonins dans le réseau paroissial au $\mathrm{xv}^{\mathrm{e}}$ siècle. Prenant à la fois des exemples provençaux (Clans, Roquebillière), et alpins (Salbertrand, Gravedona, Sorico, Bormio), L. Meiffret montre comment la vie du père, de plus en plus limitée à quelques actions récurrentes (charité, bastonnade, tentation, exorcisme), voit s'appauvrir son imaginaire potentiel. Supplantée par la vogue des héros antiques et par de nouveaux modèles spirituels, l'iconographie antonine perd petit à petit au début du XVI $I^{e}$ siècle sa place de premier plan.

7 Tout en précisant que l'extrême abondance des thèmes et leur variabilité rendent difficile le travail de synthèse, L. Meiffret propose heureusement un bilan d'évolution des familles typologiques qui permet d'avoir une vision plus globale des thèmes, des œuvres et des commanditaires excessivement divers décrits au fil du texte. Des tableaux synthétiques permettent enfin de visualiser les évolutions iconographiques et la variabilité des ordres commanditaires.

8 Cette étude offre finalement le double intérêt de présenter de brèves monographies chronologiques sur chacun des sites étudiés, dont beaucoup étaient presque inconnus jusqu'ici, et de donner à voir de manière générale l'évolution de la représentation en Italie d'un saint primordial aux deux derniers siècles du Moyen Âge; ce qui en fait d'emblée un ouvrage de référence sur le sujet. 